\title{
Quantitative Computed Tomography in COPD: Possibilities and Limitations
}

\author{
O. M. Mets • P. A. de Jong • B. van Ginneken • \\ H. A. Gietema · J. W. J. Lammers
}

Received: 27 June 2011/ Accepted: 28 November 2011/Published online: 17 December 2011

(C) The Author(s) 2011. This article is published with open access at Springerlink.com

\begin{abstract}
Chronic obstructive pulmonary disease (COPD) is a heterogeneous disease that is characterized by chronic airflow limitation. Unraveling of this heterogeneity is challenging but important, because it might enable more accurate diagnosis and treatment. Because spirometry cannot distinguish between the different contributing pathways of airflow limitation, and visual scoring is time-consuming and prone to observer variability, other techniques are sought to start this phenotyping process. Quantitative computed tomography (CT) is a promising technique, because current CT technology is able to quantify emphysema, air trapping, and large airway wall dimensions. This review focuses on CT quantification techniques of COPD disease components and their current status and role in phenotyping COPD.
\end{abstract}

Keywords Computed tomography - Airway remodeling · Pulmonary emphysema - Chronic obstructive pulmonary disease - Quantitative CT

O. M. Mets $(\varangle) \cdot$ P. A. de Jong · H. A. Gietema

Department of Radiology, University Medical Center Utrecht, Huispostnummer E01.132, Postbus 85500, 3508 GA Utrecht,

The Netherlands

e-mail: o.m.mets@umcutrecht.nl

B. van Ginneken

Diagnostic Image Analysis Group, Department of Radiology, Radboud University Nijmegen Medical Centre, Nijmegen,

The Netherlands

J. W. J. Lammers

Department of Pulmonology, University Medical Center Utrecht, Utrecht, The Netherlands

\section{Introduction}

Chronic obstructive pulmonary disease (COPD) is currently simply defined as chronic airflow limitation that is not fully reversible; however, in reality COPD is a complicated group of disorders with a range of pathological changes in the lung, extrapulmonary effects, and comorbidities, which all may contribute to the severity of the disease [1-5]. In the lungs, parenchymal destruction (emphysema), small airways disease, large airways disease, and possibly other factors contribute to the airflow limitations in varying degrees. Unraveling of this heterogeneity is challenging but important, because early detection of these pathologies might enable more accurate and earlier diagnosis and might lead to more specific therapeutic options. Quantitative computed tomography (CT) may be a highly interesting modality to detect these pathologies in vivo, because its separate analysis of disease components may allow morphologic phenotyping and visual evaluation of CT images for pathology is time-consuming and prone to considerable observer variability [6].

During the past decades, quantitative CT has increasingly been used to assess lung structure [7], and considerable research efforts have been devoted to emphysema quantification. In addition, several research groups have worked on tools to quantify large airway wall morphology. There are strong suggestions that emphysema-dominant and airway wall thickening-dominant groups of COPD patients can be separated by quantitative CT [8]. Until recently, only little work has been presented on the quantification of small airways disease, even though the small airways are the most important site of airflow obstruction in COPD [9-12]. This review summarizes and illustrates the current status of CT quantification methods for the several COPD components, and we discuss the current 
Table 1 Current status and future directions of quantitative computed tomography in COPD

\begin{tabular}{|c|c|}
\hline Current status & $\begin{array}{l}\text { It is now technically possible to quantify } \\
\text { emphysema, air trapping, and large airway } \\
\text { dimensions on CT scans of COPD patients. } \\
\text { Previous studies have shown good correlation } \\
\text { with histology and clinical measures. In } \\
\text { general, more extensive evidence is available } \\
\text { for CT emphysema quantification; less } \\
\text { evidence is available for large airway } \\
\text { dimensions and small airways disease } \\
\text { quantification }\end{array}$ \\
\hline $\begin{array}{l}\text { Future technical } \\
\text { directions }\end{array}$ & $\begin{array}{l}\text { Future studies could further address the } \\
\text { influence of } \mathrm{CT} \text { scanning parameters and } \\
\text { volume correction during acquisition }\end{array}$ \\
\hline $\begin{array}{l}\text { Future clinical } \\
\text { application }\end{array}$ & $\begin{array}{l}\text { More studies are needed on the practical value } \\
\text { of quantitative CT for early diagnosis, } \\
\text { prediction of outcome, and disease } \\
\text { phenotyping }\end{array}$ \\
\hline
\end{tabular}

status and future possibilities of phenotyping COPD by quantitative CT (Table 1).

\section{Emphysema Quantification}

Pulmonary emphysema involves alveolar wall destruction and apoptosis of epithelial and endothelial cells caused by repeated injury and repair after inhalation exposure of cigarette smoke and other noxious particles [1]. Emphysema can be subdivided into centrilobular, panlobular, bullous, and paraseptal emphysema, which show different distribution throughout the lung; for example, the lower lobe predominance of panlobular emphysema in alfa-1antitrypsin deficiency (AATD) versus the distal and subpleural distribution of paraseptal emphysema [13]. This difference in distribution may be of importance when single CT images are evaluated; however, in volumetric assessment of the lungs this is not. In assessment of the emphysema extent, quantitative analysis should be preferred over visual scores [14], because quantitative assessment of emphysema provides a continuous instead of a categorical score, which is important in disease followup. Emphysema quantification has been shown to be highly reproducible [15-18]; however, data on the limits of agreement, which are important to define actual increase in longitudinal use, are currently still limited. Nevertheless, it is to be expected that when correction for lung volume is applied, quantitative $\mathrm{CT}$ assessment of emphysema will be near perfectly reproducible.

The first study to quantify emphysema severity with CT was performed by Hayhurst and colleagues, who showed that Hounsfield Unit (HU) frequency distribution curves of patients with histologically proven emphysema significantly differed from patients without emphysema [19]. Four years later, an objective method that highlights voxels below a fixed threshold, the "density mask," was introduced (Fig. 1) [20]. Emphysema severity is generally quantified as the "low attenuation area" (LAA) in the lung with HU less than a fixed density threshold (e.g., -950 $\mathrm{HU}$; LAA_950). Another method is using the nth cutoffpercentile in the attenuation distribution curve, which provides the density value in $\mathrm{HU}$ under which $\mathrm{n} \%$ of the voxels is distributed [7,21, 22]. Over time, several density thresholds have been proposed in the literature to separate emphysematous from nonemphysematous lung [7, 21-23]. The first density threshold proposed by Muller and coworkers [20] was at $-910 \mathrm{HU}$, because this cutoff value yielded the best correlation between emphysema in resected lung tissue and CT measurements in contrast-enhanced 10-mm-thick slices, obtained on a single-slice scanner. Gevenois et al. later reported the strongest pathologic correlation with emphysema at macroscopic [24] and microscopic [25] level at a threshold of $-950 \mathrm{HU}$ in 1-mm noncontrast-enhanced high-resolution filtered images. More recently, Madani et al. observed that thresholding at -960 to $-980 \mathrm{HU}$ best reflects the extent of emphysema for multidetector CT (MDCT) scans with slice-thicknesses of $1.25,5.0$, and $10.0 \mathrm{~mm}$, at 20 or $120 \mathrm{mAs}$ [23]. These thresholds yielded the strongest correlation with macroscopic and microscopic extent, although all thresholds lower than $-910 \mathrm{HU}$ were significantly correlated with
Fig. 1 Quantitative emphysema measure. Axial CT images of the thorax in inspiration showing emphysema (left) and densitometry overlay at a threshold of -950 Hounsfield Units (right). Voxels with attenuation below the set threshold are colored white

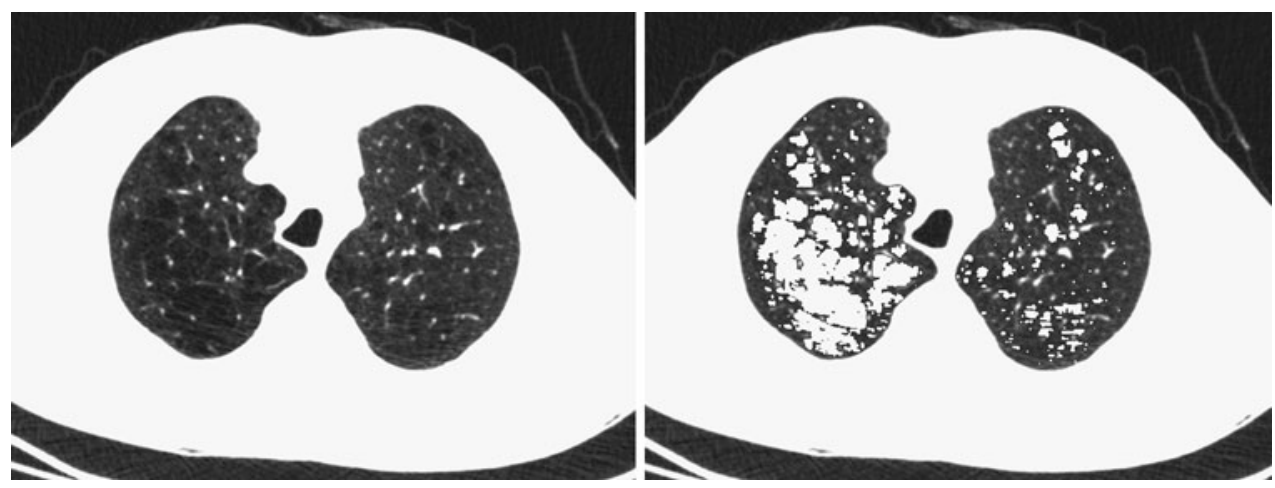


histopathological indices [23]. For longitudinal emphysema studies, percentile densitometry with the 15 th percentile is reported to be recommended [26]. Recently, Madani et al. demonstrated that the first percentile showed the highest correlation with macroscopic and microscopic emphysema in 1-mm MDCT images [23]. However, all cutoffs below the 18th percentile were significantly correlated with histopathology [23]. The above shows that there is a range of approaches possible, and until today there is no final consensus regarding the optimal cutoff in percentile method or threshold value, especially not for low-dose multidetector CT scans [27].

\section{Factors that Influence Quantitative Measurements}

Densitometry can be influenced not only by the applied percentile or density threshold, but also by image reconstruction algorithm [28-31], section thickness [28, 32], inspiration level [15, 33], scanner/study centre [15], gravity [34] and radiation dose [35]. Madani and colleagues recently showed significant differences in emphysema measurements at varying inspiration levels, but they suggested that this may not be clinically relevant above $90 \%$

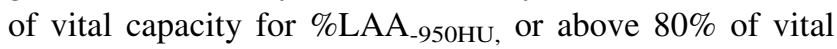
capacity for the 1st percentile method [33]. Bakker et al. has stated that CT densitometry is highly reproducible, and interscan variability of emphysema measurements largely originates from differences between scanners and severity of disease, especially when corrected for differences in total lung volume [15]. Therefore, it is argued that scans should be corrected for lung volume $[36,37]$. When multiple scanners are involved, scans can be corrected by calibrating for tracheal air [38]. To correct for the physiological ventrodorsal gradient in lung attenuation due to gravity, an automatic robust linear fit correction is suggested [34]. Currently, corrections are not widely applied. Further, application of dose reduction is important. When the radiation dose is reduced, the signal-to-noise ratio is lowered which could possibly lead to unreliable quantitative measurements. Studies on the effects of radiation dose are not conclusive; several studies reported that dose reduction can be applied without clinical importance [32, 39-41], but others did found a significant difference in quantitative emphysema measurements between high-dose and low-dose [35]. Additionally, to lessen the problem of increased noise in low-dose scanning, the application of a noise reduction filter may be useful [42]. Taken together, low dose scanning is feasible, as long as scanning protocol is taken into account in comparison of results between different studies or in follow-up.

Besides the technical factors that interact with emphysema quantification, co-existing high-density lung disease [43, 44] and low-density air trapping (Fig. 2) [10, 45] may influence the quantitative assessment of emphysema. Interstitial lung disease (i.e. fibrosis) or air trapping can alter the lung attenuation, 'masking' or aggravating emphysema measurements. This emphasizes the necessity of combined analysis of the different COPD components (Table 2).

\section{Less Commonly Used Quantification Methods}

Several other quantification methods have been reported, but these are less often used. Coxson et al. [46] described a method in which the remaining amount of lung tissue is quantified. They expressed lung inflation as $\mathrm{ml}$ of air per gram lung tissue, and showed that emphysematous lesions below and above $5 \mathrm{~mm}$ diameter corresponded with 6.0-10.2 and $>10.2 \mathrm{ml}$ air per gram lung tissue,

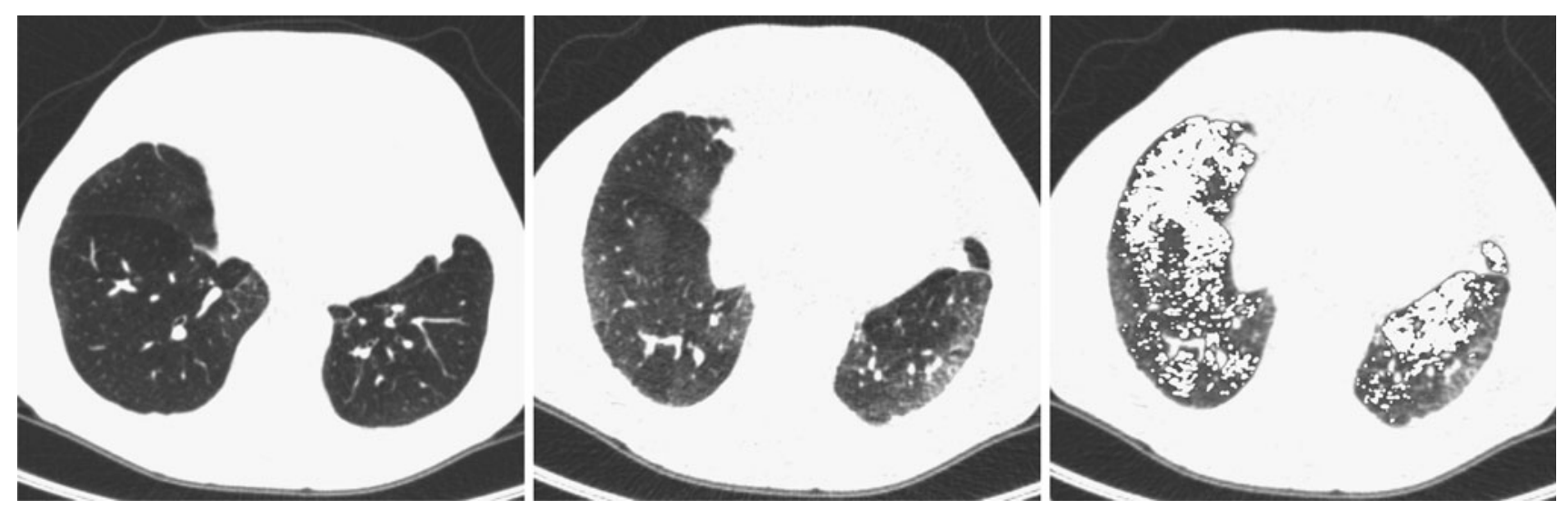

Fig. 2 Quantitative air trapping measure. Axial CT images of the thorax in inspiration (left) and expiration (middle, left) showing air trapping as sharply defined areas with less than normal increase in lung attenuation and lack of volume reduction after expiration (middle), and the densitometry overlay at a threshold between -860 $\mathrm{HU}$ and $-950 \mathrm{HU}$ (right). Voxels with attenuation within this range are colored white 
Table 2 Challenges to be solved in quantitative computed tomography in COPD

\begin{tabular}{lc}
\hline Challenge & Specific study \\
\hline $\begin{array}{l}\text { Multicenter studies with CT } \\
\text { scanners from multiple vendors }\end{array}$ & $\begin{array}{c}\text { Suitability and influence of } \\
\text { tracheal air correction on the } \\
\text { quantitative measures of } \\
\text { emphysema and air trapping }\end{array}$ \\
Longitudinal data & $\begin{array}{c}\text { Interscan variability and limits of } \\
\text { agreement of the quantitative } \\
\text { measures. Methods of proper } \\
\text { lung volume control or volume } \\
\text { standardization }\end{array}$ \\
Low-dose CT scanning & Influence of noise reduction \\
& filtering and iterative \\
reconstructions on quantitative & CT measures \\
Lack of consensus on which & Comparison of the available \\
measures to use, multiple & quantitative measures against \\
software tools & reference standards \\
\hline
\end{tabular}

respectively. Others have developed more technical, texture-based quantification methods, applying parenchymal classifications and a large number of independent tissue features [47-52]. Texture-based measurements were reported to correlate significantly better with PFT than density-based measurements [51, 52]. Finally, a fractalbased concept was introduced to assess the size distribution of low attenuation regions. Mishima et al. determined the slope of the cumulative frequency-size distributions of areas below $-960 \mathrm{HU}$ on a log-log scale ( $D$-value) [53], and based on their results they suggest that the $D$-value is a robust parameter and powerful index of terminal airspace enlargement, and a potential method of emphysema quantification [53]. Its pathological validity is questioned [54], but Yuan et al. recently showed that D-value is independently and significantly correlated with histological measurements of emphysema and that the combination of cluster analysis and lung densitometry provides a more accurate result than either measure alone [44].

In conclusion, CT scanning is commonly used for emphysema quantification, and pathological correlation studies are available. However, the debate about both the most appropriate scan technique and algorithm has not been settled yet. As long as different techniques and settings are used, strict comparison of studies should be performed with great caution, because many factors influence the automated quantitative results.

\section{Large Airway Measurements}

Large airways can be thickened in COPD, an abnormality shown to correlate with pulmonary function tests [55]. It also has been shown that bronchial wall thickening is an independent determinant of airflow obstruction in COPD subjects [56, 57]. Structurally, the changes in proximal airways of COPD subjects involve squamous metaplasia of epithelium and mucus hypersecretion [1]. It has been suggested that thickening of the wall of larger airways reflects small airway abnormalities [58], but whether large airway wall thickening merely reflects small airways disease or is an independent morphologic phenotype of COPD remains to be determined.

Initial studies on large airway quantification relied on manual tracing of airways on CT images [59], but developments in scanner technology led to the introduction of multiple techniques [60-69]. The most widely used method in airway measurements is the "full-width-at-half-maximum" (FWHM) principle. Briefly, the FWHM technique calculates the x-ray attenuation values along rays placed from the lumen center outwards in all directions (Fig. 3). The airway wall boundaries are considered to be at the location where attenuation is halfway to the maximum on the lumen side and halfway to the minimum on the parenchymal side (Fig. 4) [64, 70]. From the airway wall delineations, different parameters, such as wall thickness, lumen area, wall area percentage, and airway perimeters, can be calculated [71]. Although the FWHM technique is standardized and straightforward, it systematically overestimates airway wall area, especially in small airways [64]. Several other techniques were described to increase accuracy. First, a phantom study showed greater accuracy compared with FWHM in measuring the airway inner and outer radius of thin-walled airways with the use of a maximum-likelihood algorithm on the gray level along a calculated ray [60]. Second, Saba et al. reported a method of ellipse-fitting to the airway lumen and wall of a phantom that significantly improves estimation of the luminal edges and is able to estimate airway geometry to within 4 degrees in tilt of obliquely cut airways [61]. Third, a score-guided erosion algorithm showed significantly lower overestimation of airway wall area in a phantom and excised pig lung compared with manual delineation. Their method combined an edge-finding algorithm with the knowledge that airways are roughly circular and of high density to lung parenchyma [62]. Last, Weinheimer et al. presented an integral based method by which the blurring effect of CT, especially present in small objects, is minimized. They showed that their method performed much better than the FWHM method in a silicon tube phantom. Also, their method proved repeatable in pigs and was able to discriminate between smokers and nonsmokers in their trial [63].

Using multiplanar reconstruction, Hasegawa et al. showed that airway wall dimensions at the sixth generation were more closely associated with lung function than dimensions of more proximal generations [67]. This finding is supported by 

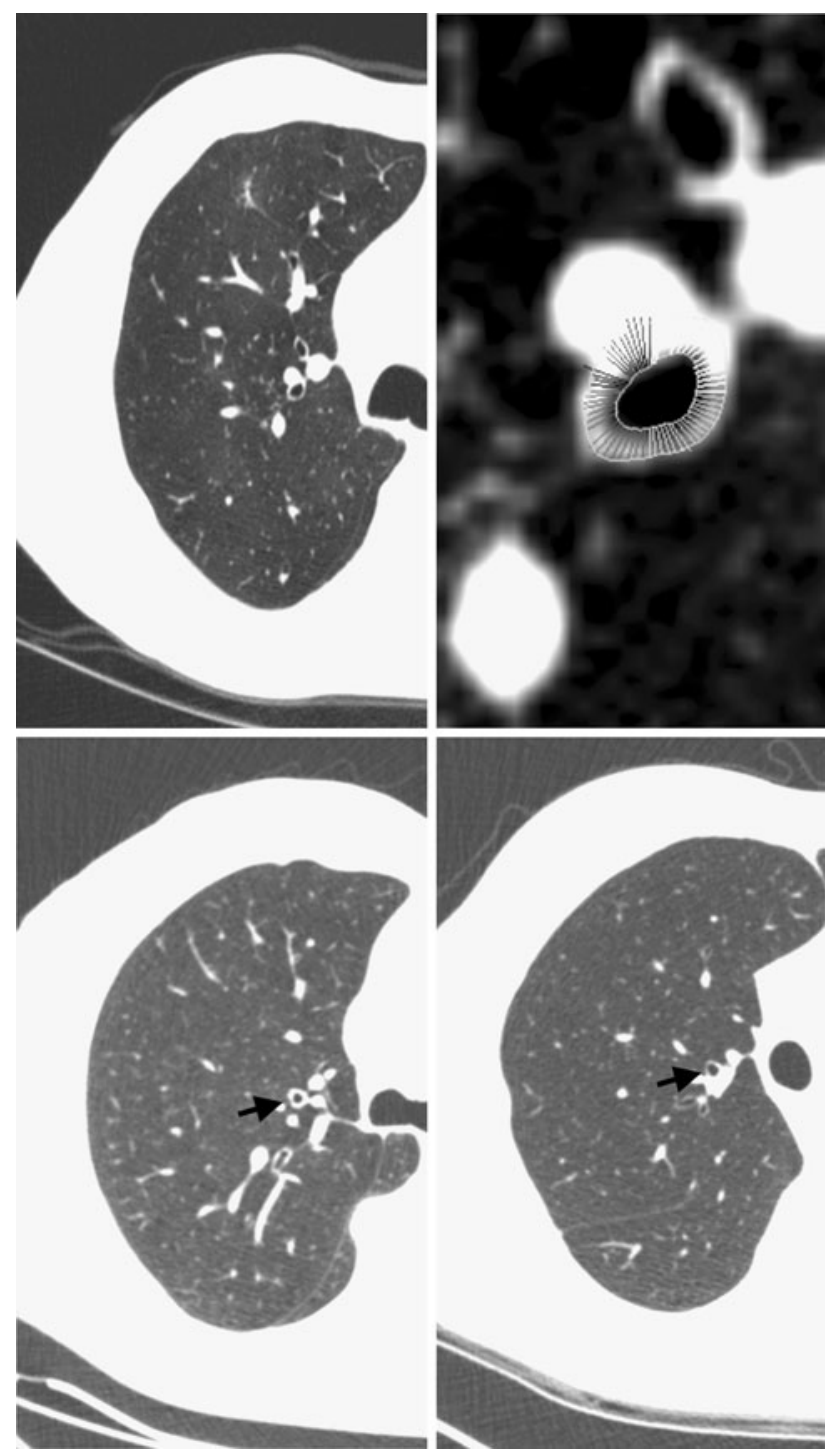

Fig. 3 Quantitative measurement of the large airway dimensions. An axial CT image of the right lung at the level of the upper right apical bronchus (upper left). A magnified image of this airway is shown with rays flowing out of a center point in the airway lumen in all directions, as well as the defined inner and outer edge of the airway wall (upper right). Additionally, two examples are shown with a thickened airway wall (lower left, black arrow) and a normal airway wall (lower right, black arrow). The wall area percentage (\%WA) is $84 \%$ and $65 \%$, respectively

Achenbach and colleagues who assessed airway wall dimensions in smokers with COPD and never smokers with 3D software [68]. They reported moderate correlations $(-0.56<r<-0.62)$ between airway wall measurements and airflow obstruction (FEV1 and \%predictedFEV1), and demonstrated stronger correlations when only small airways were analyzed. Matsuoka et al. [69] were the first to perform airway measurements in expiration, using phantom-validated 3D software. The authors demonstrated that luminal area in expiration correlated more closely with airflow limitation than

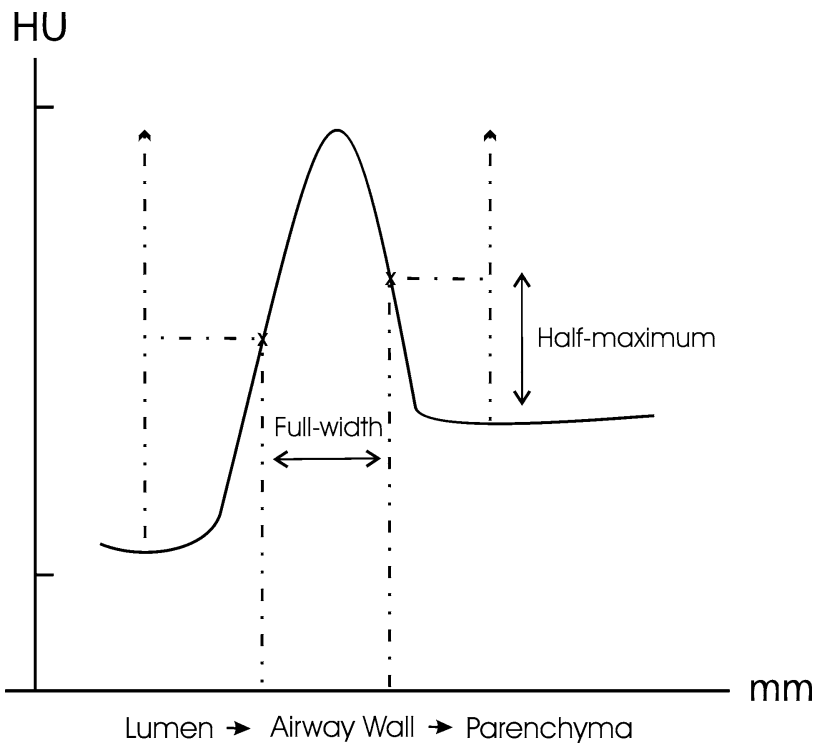

Fig. 4 Graphical illustration of the full-width-at-half-maximum (FWHM) method. An illustration of the attenuation profile along an outwards flowing ray from the luminal center-point through the airway wall (Fig. 3). In the full-width-at-half-maximum (FWHM) method, the inner and outer airway wall boundaries are assumed halfway to the maximum on the lumen side and halfway to the minimum on the parenchymal side (half-maximum), respectively. The airway wall thickness is assumed the distance between both points (full-width)

did measurements in inspiration and that the highest correlation was found for the expiration to inspiration ratio of lumen area. Furthermore, they showed that the correlation improved from the third to the fifth generation (maximum $0.70<\mathrm{r}<0.72$ ) [69]. These results extend the finding by Hasegawa and suggest that both airway wall and luminal area show stronger relations to airflow limitation in more peripheral airways. Recently, bronchial wall attenuation was introduced as another index for airway abnormality in COPD subjects; in thin walled structures, such as more peripheral airways, this peak wall attenuation is thought to represent both airway wall density and wall thickness $[72,73]$. In this study, Yamashiro et al. further solidifies the observation of stronger correlations in more peripheral airways, both for the airway wall attenuation, airway wall dimensions, and luminal area [73].

\section{Factors that Influence Quantitative Measurements}

Technically, quantitative airway measurements may be influenced by partial volume averaging [74]. Furthermore, the applied reconstruction kernel significantly affects airway wall and luminal measurement results of the FWHM method, whereas slice thickness and field of view (FOV) apparently do not [75]. Contrarily, it has been reported by 
Achenbach et al. that the pixel size does affect the accuracy of the FWHM method [76]. Reconstruction kernel influence was further investigated by Schmidt et al. who reported minor bias in measurements across soft and hard reconstructions [77]. Lowering the radiation dose was found to affect FWHM-based measurements of lumen diameter and wall thickness in pig airways [78]. Contrarily, others found no influence of radiation dose on the accuracy of their algorithm in low-dose scans at $50 \mathrm{mAs}$ [79]. Evidence on the effect of lung volume on quantitative assessment of airway dimensions in humans is lacking. Lastly, longitudinal data for the different airway quantification techniques are limited, but variability between CT measurements may be substantial and impair measurements, especially in smaller airways [80].

In conclusion, the wall of larger airways is directly visible on CT and can be thickened in COPD patients. Quantification methodology has developed during the past decade into automated 3D-programs. Future studies are required to determine the pathological validity of the newer 3D quantification techniques, and further research should investigate the influence of CT scan parameters and interscan reproducibility of the different airway quantification methods available.

\section{Small Airways Measurements}

The most important site of airflow obstruction in COPD are the airways smaller than $2 \mathrm{~mm}[11,12]$. Structurally, this involves airway wall thickening, airway narrowing, peribronchial fibrosis, and luminal inflammatory mucous exudate [1]. These small airways cannot be visualized directly using current CT scanners, but the presence of air trapping on expiratory CT scans can be used as an indirect sign to evaluate small airways dysfunction. Air trapping is defined as less than normal increase in lung attenuation and lack of volume reduction after expiration (Fig. 2) [13]. Quantification of air trapping is challenging in COPD patients, because it should be separated from air remaining in emphysematous spaces after exhalation [10]. In addition, air trapping is an unspecific phenomenon, because it is reported in nonobstructive smokers and healthy individuals with normal PFT as well [81-86]. Finally, there is no pathological reference available, because air trapping is an in vivo phenomenon.

CT quantification of air trapping has not been widely used in COPD subjects. Recently, the percentage of lung voxels below $-856 \mathrm{HU}$ in expiration has been introduced as a measure of air trapping in COPD [87]. This expiratory threshold of $-856 \mathrm{HU}$ is a conversion of $6.0 \mathrm{ml} / \mathrm{g}$ lung inflation in inspiration [46], and it has been has been used before in air trapping quantification in asthmatic children
[88]. The drawback of this single-threshold method is that it does not compensate for the influence of emphysematous areas; it combines air trapping and emphysema quantification into one measure. Previously, the expiratory to inspiratory ratio of mean lung density (E/I-ratio $\left.{ }_{\mathrm{MLD}}\right)$, as a measure of air trapping, was shown to correlate $(0.48<\mathrm{r}<0.68)$ with clinical parameters of COPD such as BODE-index [45]. Yamashiro and colleagues [9] used the expiratory to inspiratory ratio of lung volume (E/Iratio $_{\mathrm{LV}}$ ) and showed that his volume-ratio correlated almost perfectly $(\mathrm{r}=0.95 ; p<0.001)$ with the $\mathrm{E} / \mathrm{I}-$ ratio $_{M L D}$. Nevertheless, this air trapping measures may clearly be influenced by the expiratory effort, and scanning should be performed after standardized instructions. Matsuoka et al. [10, 89] developed a density-based quantification method for air trapping that is designed specifically to quantify air trapping outside emphysematous areas. To exclude emphysema, all voxels with attenuation lower than $-950 \mathrm{HU}$ were excluded from inspiration and expiration scans. In these limited lungs, a threshold of -860 HU delivered the highest correlation with spirometry and RV/TLC. They subsequently calculated the relative volume change between $-860 \mathrm{HU}$ and $-950 \mathrm{HU}\left(\mathrm{RVC}_{-860}\right.$ to -950) using the formula: $R V C_{-860}$ to $-950=$ expiratory volume between -860 and $-950 \mathrm{HU}$-inspiratory volume between -860 and $-950 \mathrm{HU}$. Their measure correlated significantly with lung function parameters of airflow obstruction and air trapping $(r=0.50-0.80)$ in subjects with either minimal-to-mild emphysema or moderate-tosevere emphysema [10]. In a feasibility study, Torigian et al. [90] attempted to register accurately inspiration and expiration scans to obtain a colored "difference-image." Further research into this method is required to improve precision and accuracy. To date, no comparison of the published quantitative CT measures of air trapping has been performed, and the optimal quantitative measure has yet to be identified.

Factors that Influence Quantitative Measurements

Quantification of air trapping in expiratory scans is clearly influenced by the level of expiration, but the influence of suboptimal expiration on air trapping quantification has not been studied. Scanning should be performed after strict breathing instructions, but standardization of expiration level also could be achieved by using spirometric-gated scanning, a technique that is technically cumbersome and not widely used in clinical practice. It is currently not known whether such standardization will improve the repeatability of quantitative assessment of air trapping. Furthermore, noise in low-dose scans may influence the quantitative measurements similar to emphysema quantification. At the moment, no noise reduction filter is 
validated to eliminate the influence of increased image noise for air trapping quantification. No studies have addressed section thickness and other scan parameters on quantitative CT measurements of air trapping. Last, presence of emphysematous areas may influence quantitative assessment of air trapping. Techniques that compensate for emphysema are theoretically preferred; however, to date no studies are available that compare corrected and uncorrected quantitative $\mathrm{CT}$ air trapping measures.

In conclusion, small airways cannot be directly visualized with current CT technology, but air trapping quantification at end-expiratory CT scans can be used as an indirect measure of small airways disease. Literature in this relatively new research area is still limited, and it is yet unknown what is the optimal quantitative CT air trapping method in COPD.

\section{Other Possible Quantifiable Abnormalities}

The extent of airflow limitation in COPD may not be fully explained by emphysematous tissue loss, small airways disease, and large airway remodeling alone. Hence, several other morphologic CT signs (e.g., intrapulmonary airway collapse [91], tracheobronchomalacia [92], mucous plugging, bronchiectasis, or interstitial lung disease) might be involved and could possibly be quantified. However, to our knowledge, these components have not been investigated with quantitative CT techniques so far.

\section{Use of Quantitative CT in COPD}

\section{Correlation with Disease Parameters}

A small number of studies, as summarized below, have investigated the relationship between quantitative CT measures and some commonly used clinical measurements. The number of publications limits the interpretation on which CT parameters correlated best with a certain clinical parameter. Quantitative CT emphysema has been shown to be associated with osteoporosis [93, 94], exercise capacity (6-minute walk distance, 6MWD) [45, 95], and the BODE index (a multicomponent parameter that includes BMI, $\mathrm{FEV}_{1}$, dyspnoe-score and exercise capacity as measured with the 6MWD) $[45,96]$. Additionally, it has been shown that quantitative CT air trapping is associated with 6MWD [45] and that quantitative CT measurements of airway wall thickness and emphysema are associated with exacerbation frequency in COPD subjects [97]. Also, CT measurements of emphysema and airway wall thickness are independently related to patient reported respiratory symptoms [98]. Recently, it has been shown that the combination of quantitative CT emphysema and CT air trapping explains a large part of the variation in airflow limitation in COPD [99]. Finally, it has been reported that CT assessed emphysematous changes correlated with respiratory mortality in various stages of COPD [100]. These are all interesting findings that may lead the way to a clinical application of quantitative CT; however, all studies are relatively small and need further validation. Future studies will have to expand the knowledge on the associations between quantitative CT measures and relevant disease parameters.

\section{Clinical Application}

Possible clinical application of quantitative CT has been studied in lung volume reduction surgery (LVRS) patients. Cederlund et al. [101] used densitometry at $-950 \mathrm{HU}$ to separate heterogeneous from homogeneous distribution of emphysema and suggested further research to determine its value in patient selection and postoperative outcome in LVRS. Nakano et al. [102] showed that LVRS candidates with emphysema distribution in the rind of upper lung fields had greater benefit from this treatment than those with emphysema at other locations. Additionally, Flaherty et al. found that upper zone emphysema was the best predictor of $\mathrm{FEV}_{1}$ increase after surgery [103], and Martinez et al. [104] showed that lower zone predominance was predictive of mortality. Furthermore, it was demonstrated that CT measurements of emphysema before LVRS predict postsurgery cardiopulmonary exercise capacity [105]. These results all support the promising role of quantitative CT assessment in patient selection and outcome prediction in LVRS; however, it is questionable whether a preoperative radiological measure alone can sufficiently predict functional outcome of LVRS; it is more likely that CT will serve as an additive tool.

Longitudinal studies regarding both clinical and quantitative CT data are important in requiring insight into the structural changes over time, the contribution of different disease components to functional decline, and the effect throughout different stages of the disease. In this area, quantitative CT measures have been used recently as outcome measure; Stockley et al. showed that alpha-1-antitrypsine augmentation significantly reduces CT lung density decline, which represented emphysema increase and may therefore reduce mortality risk [106]. Parr et al. showed that sputum markers of neutrophilic inflammation in COPD correlated with disease progression, indicated as quantitative CT measures [107]. Using quantitative CT emphysema measures as outcome variable originates from the study by Dirksen et al. [108], which showed that spirometry is less sensitive than CT lung density for the 
detection of emphysema progression. Later studies underlined this superiority of quantitative CT over spirometry for the detection of disease progression in alfa-1-antitrypsine deficiency [109-111]. Other longitudinal studies into CT emphysema quantification provided information that quantitative measurements of overinflation [112] and emphysema [38] at baseline predict greater decline in lung function over time. These data illustrate the expanding use of CT emphysema assessment in longitudinal research, and it is to be expected that quantitative CT will increasingly be used to monitor disease progression and therapy effects. However, although some studies have reported on the reproducibility of emphysema measurements [15-18], more knowledge on the limits of agreement is needed before widespread use of quantitative CT emphysema measures in longitudinal studies.

Also of interest is the longitudinal assessment of airway dimensions and air trapping using quantitative CT. Ohara et al. [113] found that annual changes in airway thickening correlated with annual decline in lung function; however, there is very little evidence and certainly no consensus on how to obtain and compare data on large and small airways in COPD. Future studies should establish a general approach, validation against pathology, and elucidate the reproducibility and limits of agreement of different quantification methods. Additionally, they should provide further data on the association between clinical parameters and airway wall thickening and air trapping, and on the predictive value of these measures for lung function decline.

\section{Possible Role in Phenotyping}

It has become a widespread belief that different phenotypes exist within COPD and that these phenotypes may require different management and treatment. Quantitative CT might be a good starting point because well-known relevant pathology can be detected in vivo. Nakano et al. [70] quantified the airway wall of the upper right apical bronchus and emphysema extent in 114 subjects and found that both airway dimensions and parenchymal destruction are independent contributors to lung function. They further showed that most subjects showed either airway- or emphysema-dominant disease $[8,70]$.

Makita et al. showed that emphysema extent varies widely within the same disease stage, suggesting that there are subjects with emphysematous disease and small airways disease [114]. Patel et al. provided further evidence for phenotypes by showing that airway wall thickening and emphysema dominance follows familial aggregation [57]. Within emphysema, small airway wall thickening has been shown to occur in both centrilobular and panlobular phenotypes, however, is more closely associated with emphysema and airflow limitation in the centrilobular phenotype [115]. It also has been reported that emphysematous COPD subjects have a different disease phenotype compared with nonemphysematous COPD subjects; i.e., lower spirometry, diffusion constant, radiological scores of chronic bronchitis, and more sputum lymphocytes [116]. Regarding airway-dominant phenotypes, it has been shown that COPD subjects with chronic bronchitis had thicker airway walls than COPD subjects without chronic bronchitis [117]. Finally, Alford et al. reported a more mechanistically oriented phenotyping method based on heterogeneity of pulmonary perfusion in emphysema susceptible smokers [118].

As the literature shows, different characteristics have been named phenotypes over time. Recently, a clear definition was proposed to classify COPD subjects in relation to clinically meaningful outcomes [119]. In line with this, it has been shown that increase in CT emphysema and airway wall thickness is associated with exacerbation frequency, which suggests that quantitative CT may help in the identification of subgroups with exacerbations for targeted research or phenotype specific therapy [97]. Such phenotyping and focused intervention is likely to be clinically meaningful; therapeutic intervention directed against inflammation of airways may be useful in airway dominant COPD; however, it might be useless or theoretically even harmful in subjects with an emphysema dominant phenotype. Fujimoto and Kitaguchi $[120,121]$ underline this rationale by demonstrating different responsiveness to drugs in patients with visual predominant airway, emphysema, or mixed disease. Future studies should provide more evidence on phenotyping and clinical outcomes. Currently, large studies, such as ECLIPSE, COPDgene, and SPIROMICS, are on their way to gather data systematically for COPD subjects and to provide new information to further unravel this complex disease.

\section{Additional Diagnosis of COPD}

With the increased use of $\mathrm{CT}$ in both daily practice and lung cancer screening trials, where pulmonary function testing is not performed routinely, quantitative CT might become a useful tool for the detection of new COPD subjects. First, given the strong relationship between airflow limitation and quantitative CT measurements of emphysema and air trapping [99], quantitative CT may be used additionally to identify airflow obstruction from CT scans obtained for another reason [122]. Second, CT holds the potential to predict lung function decline $[38,112]$ and to identify COPD cases still in their subclinical stage (i.e., normal pulmonary function test) based on morphologic CT features [38]. However, evidence on the additive value for COPD detection in CT is still limited and more research is warranted to further explore this application of $\mathrm{CT}$ data. 


\section{Radiation Exposure in Quantitative CT}

Radiation dose and risks are important issues in studies involving CT imaging. Image noise is an important related issue for quantitative CT on low-dose scans. Briefly, noise represents random fluctuations of the measured CT number in scans; thus, image noise will increase when radiation dose is lowered. Quantitative CT is possible with low-dose protocols with effective dose around $0.5-1.5 \mathrm{mSv}$ (annual background radiation in the United States is around $3 \mathrm{mSv}$ ) [123]. Even when individuals are exposed multiple times (e.g., lung cancer screening trials), the cumulative dose remains fairly low. However, risk should always be balanced to expected benefit.

\section{Conclusions}

The detection of relevant COPD phenotypes is a challenging and exciting research priority. Since quantification techniques have been improved during the past decades, CT can now measure the well-known disease components in COPD, such as emphysema, small airways disease, and large airways disease; this makes quantitative CT very promising in COPD research. However, a lot of work remains, especially in the quantitative assessment of small airways dysfunction. Quantitative CT might gain an important role in both phenotyping and (early) diagnosis of COPD patients, which might lead to the detection of treatable COPD subgroups and prevention of morbidity and mortality due to this disease.

\section{Conflict of interest None.}

Open Access This article is distributed under the terms of the Creative Commons Attribution Noncommercial License which permits any noncommercial use, distribution, and reproduction in any medium, provided the original author(s) and source are credited.

\section{References}

1. Global Initiative for Chronic Obstructive Pulmonary Disease. Global strategy for the diagnosis, management, and prevention of chronic obstructive pulmonary disease. Updated 2010. Available at: http://www.goldcopd.com. Accessed September 2011

2. Reilly JJ (2008) COPD and declining FEV1—-time to divide and conquer? N Engl J Med 359(15):1616-1618

3. Rennard SI, Vestbo J (2008) The many "small COPDs": COPD should be an orphan disease. Chest 134(3):623-627

4. Friedlander AL, Lynch D, Dyar LA, Bowler RP (2007) Phenotypes of chronic obstructive pulmonary disease. COPD 4(4): 355-384

5. Agusti A, Calverley PM, Celli B, Coxson HO, Edwards LD, Lomas DA, MacNee W, Miller BE, Rennard S, Silverman EK,
Tal-Singer R, Wouters E, Yates JC, Vestbo J (2010) Characterisation of COPD heterogeneity in the ECLIPSE cohort. Respir Res 11:122

6. Lynch D, Jacobson F, Murphy J, Wilson C, Newell Jr J, Grenier P, Kauczor H, Crapo J (2011) Visual CT subtypes of COPD: preliminary observations from the COPDGene Trial, presented on behalf of the COPDGene Qualitative CT workshop participants. RSNA 96th scientific assembly and annual meeting. Available at: http://rsna2010.rsna.org/search.cfm?action=add\% filter $=$ Author\&value $=81026$. Accessed September 2011

7. Coxson HO, Rogers RM (2005) Quantitative computed tomography of chronic obstructive pulmonary disease. Acad Radiol 12(11):1457-1463

8. Nakano Y, Muller NL, King GG, Niimi A, Kalloger SE, Mishima M, Pare PD (2002) Quantitative assessment of airway remodeling using high-resolution CT. Chest 122(6 Suppl):271S275S

9. Yamashiro T, Matsuoka S, Bartholmai BJ, San Jose ER, Ross JC, Diaz A, Murayama S, Silverman EK, Hatabu H, Washko GR (2010) Collapsibility of lung volume by paired inspiratory and expiratory CT scans: correlations with lung function and mean lung density. Acad Radiol 17(4):489-495

10. Matsuoka S, Kurihara Y, Yagihashi K, Hoshino M, Watanabe N, Nakajima Y (2008) Quantitative assessment of air trapping in chronic obstructive pulmonary disease using inspiratory and expiratory volumetric MDCT. AJR Am J Roentgenol 190(3): 762-769

11. Hogg JC, Macklem PT, Thurlbeck WM (1968) Site and nature of airway obstruction in chronic obstructive lung disease. N Engl J Med 278(25):1355-1360

12. Hogg JC, Chu F, Utokaparch S, Woods R, Elliott WM, Buzatu L, Cherniack RM, Rogers RM, Sciurba FC, Coxson HO, Pare PD (2004) The nature of small-airway obstruction in chronic obstructive pulmonary disease. N Engl J Med 350(26):26452653

13. Hansell DM, Bankier AA, MacMahon H, McLoud TC, Muller NL, Remy J (2008) Fleischner Society: glossary of terms for thoracic imaging. Radiology 246(3):697-722

14. Cavigli E, Camiciottoli G, Diciotti S, Orlandi I, Spinelli C, Meoni E, Grassi L, Farfalla C, Pistolesi M, Falaschi F, Mascalchi M (2009) Whole-lung densitometry versus visual assessment of emphysema. Eur Radiol 19(7):1686-1692

15. Bakker ME, Stolk J, Putter H, Shaker SB, Parr DG, Piitulainen E, Russi EW, Dirksen A, Stockley RA, Reiber JH, Stoel BC (2005) Variability in densitometric assessment of pulmonary emphysema with computed tomography. Invest Radiol 40(12): 777-783

16. Stolk J, Dirksen A, van der Lugt AA, Hutsebaut J, Mathieu J, de RJ, Reiber JH, Stoel BC (2001) Repeatability of lung density measurements with low-dose computed tomography in subjects with alpha-1-antitrypsin deficiency-associated emphysema. Invest Radiol 36(11):648-651

17. Shaker SB, Dirksen A, Laursen LC, Maltbaek N, Christensen L, Sander U, Seersholm N, Skovgaard LT, Nielsen L, Kok-Jensen A (2004) Short-term reproducibility of computed tomographybased lung density measurements in alpha- 1 antitrypsin deficiency and smokers with emphysema. Acta Radiol 45(4): 424-430

18. Gierada DS, Yusen RD, Pilgram TK, Crouch L, Slone RM, Bae KT, Lefrak SS, Cooper JD (2001) Repeatability of quantitative $\mathrm{CT}$ indexes of emphysema in patients evaluated for lung volume reduction surgery. Radiology 220(2):448-454

19. Hayhurst MD, MacNee W, Flenley DC, Wright D, McLean A, Lamb D, Wightman AJ, Best J (1984) Diagnosis of pulmonary emphysema by computerised tomography. Lancet 2(8398): $320-322$ 
20. Muller NL, Staples CA, Miller RR, Abboud RT (1988) "Density mask": an objective method to quantitate emphysema using computed tomography. Chest 94(4):782-787

21. Matsuoka S, Yamashiro T, Washko GR, Kurihara Y, Nakajima Y, Hatabu H (2010) Quantitative CT assessment of chronic obstructive pulmonary disease. Radiographics 30(1):55-66

22. Lynch DA, Newell JD (2009) Quantitative imaging of COPD. J Thorac Imaging 24(3):189-194

23. Madani A, Zanen J, De Maertelaer V, Gevenois PA (2006) Pulmonary emphysema: objective quantification at multidetector row CT: comparison with macroscopic and microscopic morphometry. Radiology 238(3):1036-1043

24. Gevenois PA, De Maertelaer V, De Vuyst P, Zanen J, Yernault JC (1995) Comparison of computed density and macroscopic morphometry in pulmonary emphysema. Am J Respir Crit Care Med 152(2):653-657

25. Gevenois PA, De Vuyst P, de Maertelaer V, Zanen J, Jacobovitz D, Cosio MG, Yernault JC (1996) Comparison of computed density and microscopic morphometry in pulmonary emphysema. Am J Respir Crit Care Med 154(1):187-192

26. Newell JD Jr, Hogg JC, Snider GL (2004) Report of a workshop: quantitative computed tomography scanning in longitudinal studies of emphysema. Eur Respir J 23(5):769-775

27. Hochhegger B, Marchiori E, Irion KL, Moreira J (2010) Are we measuring pulmonary emphysema? Respir Med 104(7):1073

28. Gierada DS, Bierhals AJ, Choong CK, Bartel ST, Ritter JH, Das NA, Hong C, Pilgram TK, Bae KT, Whiting BR, Woods JC, Hogg JC, Lutey BA, Battafarano RJ, Cooper JD, Meyers BF, Patterson GA (2010) Effects of CT section thickness and reconstruction kernel on emphysema quantification relationship to the magnitude of the CT emphysema index. Acad Radiol 17(2):146-156

29. Ley-Zaporozhan J, Ley S, Weinheimer O, Iliyushenko S, Erdugan S, Eberhardt R, Fuxa A, Mews J, Kauczor HU (2008) Quantitative analysis of emphysema in 3D using MDCT: influence of different reconstruction algorithms. Eur J Radiol 65(2):228-234

30. Reske AW, Busse H, Amato MB, Jaekel M, Kahn T, Schwarzkopf P, Schreiter D, Gottschaldt U, Seiwerts M (2008) Image reconstruction affects computer tomographic assessment of lung hyperinflation. Intensive Care Med 34(11):2044-2053

31. Boedeker KL, Nitt-Gray MF, Rogers SR, Truong DA, Brown MS, Gjertson DW, Goldin JG (2004) Emphysema: effect of reconstruction algorithm on CT imaging measures. Radiology 232(1):295-301

32. Madani A, De Maertelaer V, Zanen J, Gevenois PA (2007) Pulmonary emphysema: radiation dose and section thickness at multidetector CT quantification-comparison with macroscopic and microscopic morphometry. Radiology 243(1):250-257

33. Madani A, Van Muylem A, Gevenois PA (2010) Pulmonary emphysema: effect of lung volume on objective quantification at thin-section CT. Radiology 257(1):260-268

34. Wiemker R, Opfer R, Bülow T, Rogalla P, Steinberg A, Dharaiya E, Subramanyan K (2007) Toward computer-aided emphysema quantification on ultralow-dose CT: reproducibility of ventrodorsal gravity effect measurement and correction. Proc SPIE 6514(65140O-1-65140O-11)

35. Yuan R, Mayo JR, Hogg JC, Pare PD, McWilliams AM, Lam S, Coxson HO (2007) The effects of radiation dose and CT manufacturer on measurements of lung densitometry. Chest 132(2):617-623

36. Stoel BC, Putter H, Bakker ME, Dirksen A, Stockley RA, Piitulainen E, Russi EW, Parr D, Shaker SB, Reiber JH, Stolk J (2008) Volume correction in computed tomography densitometry for follow-up studies on pulmonary emphysema. Proc Am Thorac Soc 5(9):919-924
37. Shaker SB, Dirksen A, Laursen LC, Skovgaard LT, HolsteinRathlou NH (2004) Volume adjustment of lung density by computed tomography scans in patients with emphysema. Acta Radiol 45(4):417-423

38. Mohamed Hoesein FA, de Hoop B, Zanen P, Gietema H, Kruitwagen CL, van Ginneken B, Isgum I, Mol C, van Klaveren RJ, Dijkstra AE, Groen HJ, Boezen HM, Postma DS, Prokop M, Lammers JW (2011) CT-quantified emphysema in male heavy smokers: association with lung function decline. Thorax. doi:10.1136/thx.2010.145995

39. Gierada DS, Pilgram TK, Whiting BR, Hong C, Bierhals AJ, Kim JH, Bae KT (2007) Comparison of standard- and lowradiation-dose CT for quantification of emphysema. AJR Am J Roentgenol 188(1):42-47

40. Zaporozhan J, Ley S, Weinheimer O, Eberhardt R, Tsakiris I, Noshi Y, Herth F, Kauczor HU (2006) Multi-detector CT of the chest: influence of dose onto quantitative evaluation of severe emphysema: a simulation study. J Comput Assist Tomogr 30(3):460-468

41. Koyama H, Ohno Y, Yamazaki Y, Nogami M, Murase K, Onishi Y, Matsumoto K, Takenaka D, Sugimura K (2010) Quantitative and qualitative assessments of lung destruction and pulmonary functional loss from reduced-dose thin-section CT in pulmonary emphysema patients. Acad Radiol 17(2):163-168

42. Schilham AM, van Ginneken B, Gietema H, Prokop M (2006) Local noise weighted filtering for emphysema scoring of lowdose CT images. IEEE Trans Med Imaging 25(4):451-463

43. Heussel CP, Herth FJ, Kappes J, Hantusch R, Hartlieb S, Weinheimer O, Kauczor HU, Eberhardt R (2009) Fully automatic quantitative assessment of emphysema in computed tomography: comparison with pulmonary function testing and normal values. Eur Radiol 19(10):2391-2402

44. Yuan R, Nagao T, Pare PD, Hogg JC, Sin DD, Elliott MW, Loy L, Xing L, Kalloger SE, English JC, Mayo JR, Coxson HO (2010) Quantification of lung surface area using computed tomography. Respir Res 11:153

45. Lee YK, Oh YM, Lee JH, Kim EK, Lee JH, Kim N, Seo JB, Lee SD (2008) Quantitative assessment of emphysema, air trapping, and airway thickening on computed tomography. Lung 186(3):157-165

46. Coxson HO, Rogers RM, Whittall KP, D'yachkova Y, Pare PD, Sciurba FC, Hogg JC (1999) A quantification of the lung surface area in emphysema using computed tomography. Am J Respir Crit Care Med 159(3):851-856

47. Uppaluri R, Mitsa T, Sonka M, Hoffman EA, McLennan G (1997) Quantification of pulmonary emphysema from lung computed tomography images. Am J Respir Crit Care Med 156(1): 248-254

48. Uppaluri R, Hoffman EA, Sonka M, Hartley PG, Hunninghake GW, McLennan G (1999) Computer recognition of regional lung disease patterns. Am J Respir Crit Care Med 160(2): 648-654

49. Xu Y, Sonka M, McLennan G, Guo J, Hoffman EA (2006) MDCTbased 3-D texture classification of emphysema and early smoking related lung pathologies. IEEE Trans Med Imaging 25(4): 464-475

50. Blechschmidt RA, Werthschutzky R, Lorcher U (2001) Automated CT image evaluation of the lung: a morphology-based concept. IEEE Trans Med Imaging 20(5):434-442

51. Sorensen L, Shaker SB, de Bruijne M (2010) Quantitative analysis of pulmonary emphysema using local binary patterns. IEEE Trans Med Imaging 29(2):559-569

52. Park YS, Seo JB, Kim N, Chae EJ, Oh YM, Lee SD, Lee Y, Kang SH (2008) Texture-based quantification of pulmonary emphysema on high-resolution computed tomography: comparison with density-based quantification and correlation with pulmonary function test. Invest Radiol 43(6):395-402 
53. Mishima M, Hirai T, Itoh H, Nakano Y, Sakai H, Muro S, Nishimura K, Oku Y, Chin K, Ohi M, Nakamura T, Bates JH, Alencar AM, Suki B (1999) Complexity of terminal airspace geometry assessed by lung computed tomography in normal subjects and patients with chronic obstructive pulmonary disease. Proc Natl Acad Sci USA 96(16):8829-8834

54. Madani A, Van Muylem A, De Maertelaer V, Zanen J, Gevenois PA (2008) Pulmonary emphysema: size distribution of emphysematous spaces on multidetector CT images-comparison with macroscopic and microscopic morphometry. Radiology 248(3): 1036-1041

55. Tiddens HA, Pare PD, Hogg JC, Hop WC, Lambert R, de Jongste JC (1995) Cartilaginous airway dimensions and airflow obstruction in human lungs. Am J Respir Crit Care Med 152(1): 260-266

56. Aziz ZA, Wells AU, Desai SR, Ellis SM, Walker AE, MacDonald S, Hansell DM (2005) Functional impairment in emphysema: contribution of airway abnormalities and distribution of parenchymal disease. AJR Am J Roentgenol 185(6): 1509-1515

57. Patel BD, Coxson HO, Pillai SG, Agusti AG, Calverley PM, Donner CF, Make BJ, Muller NL, Rennard SI, Vestbo J, Wouters EF, Hiorns MP, Nakano Y, Camp PG, Nasute Fauerbach PV, Screaton NJ, Campbell EJ, Anderson WH, Pare PD, Levy RD, Lake SL, Silverman EK, Lomas DA (2008) Airway wall thickening and emphysema show independent familial aggregation in chronic obstructive pulmonary disease. Am J Respir Crit Care Med 178(5):500-505

58. Nakano Y, Wong JC, de Jong PA, Buzatu L, Nagao T, Coxson HO, Elliott WM, Hogg JC, Pare PD (2005) The prediction of small airway dimensions using computed tomography. Am J Respir Crit Care Med 171(2):142-146

59. McNamara AE, Muller NL, Okazawa M, Arntorp J, Wiggs BR, Pare PD (1992) Airway narrowing in excised canine lungs measured by high-resolution computed tomography. J Appl Physiol 73(1):307-316

60. Reinhardt JM, D’Souza ND, Hoffman EA (1997) Accurate measurement of intrathoracic airways. IEEE Trans Med Imaging 16(6):820-827

61. Saba OI, Hoffman EA, Reinhardt JM (2003) Maximizing quantitative accuracy of lung airway lumen and wall measures obtained from X-ray CT imaging. J Appl Physiol 95(3): 1063-1075

62. King GG, Muller NL, Whittall KP, Xiang QS, Pare PD (2000) An analysis algorithm for measuring airway lumen and wall areas from high-resolution computed tomographic data. Am J Respir Crit Care Med 161(2 Pt 1):574-580

63. Weinheimer O, Achenbach T, Bletz C, Duber C, Kauczor HU, Heussel CP (2008) About objective 3-d analysis of airway geometry in computerized tomography. IEEE Trans Med Imaging 27(1):64-74

64. Nakano Y, Whittall KP, Kalloger SE, Coxson H, Pare PD, English JC (2002) Development and validation of human airway analysis algorithm using multidetector row CT. Proc SPIE 4683:460-469

65. Saragaglia A, Fetita C, Preteux F, Brillet P, Grenier P (2005) Accurate 3D quantification of the bronchial parameters in MDCT. Proc SPIE 5916:323-334

66. Berger P, Perot V, Desbarats P, Tunon-de-Lara JM, Marthan R, Laurent F (2005) Airway wall thickness in cigarette smokers: quantitative thin-section CT assessment. Radiology 235(3): $1055-1064$

67. Hasegawa M, Nasuhara Y, Onodera Y, Makita H, Nagai K, Fuke S, Ito Y, Betsuyaku T, Nishimura M (2006) Airflow limitation and airway dimensions in chronic obstructive pulmonary disease. Am J Respir Crit Care Med 173(12):1309-1315
68. Achenbach T, Weinheimer O, Biedermann A, Schmitt S, Freudenstein D, Goutham E, Kunz RP, Buhl R, Dueber C, Heussel CP (2008) MDCT assessment of airway wall thickness in COPD patients using a new method: correlations with pulmonary function tests. Eur Radiol 18(12):2731-2738

69. Matsuoka S, Kurihara Y, Yagihashi K, Hoshino M, Nakajima Y (2008) Airway dimensions at inspiratory and expiratory multisection CT in chronic obstructive pulmonary disease: correlation with airflow limitation. Radiology 248(3):1042-1049

70. Nakano Y, Muro S, Sakai H, Hirai T, Chin K, Tsukino M, Nishimura K, Itoh H, Pare PD, Hogg JC, Mishima M (2000) Computed tomographic measurements of airway dimensions and emphysema in smokers. Correlation with lung function. Am J Respir Crit Care Med 162(3 Pt 1):1102-1108

71. Coxson HO, Mayo J, Lam S, Santyr G, Parraga G, Sin DD (2009) New and current clinical imaging techniques to study chronic obstructive pulmonary disease. Am J Respir Crit Care Med 180(7):588-597

72. Washko GR, Dransfield MT, Estepar RS, Diaz A, Matsuoka S, Yamashiro T, Hatabu H, Silverman EK, Bailey WC, Reilly JJ (2009) Airway wall attenuation: a biomarker of airway disease in subjects with COPD. J Appl Physiol 107(1):185-191

73. Yamashiro T, Matsuoka S, Estepar RS, Dransfield MT, Diaz A, Reilly JJ, Patz S, Murayama S, Silverman EK, Hatabu H, Washko GR (2010) Quantitative assessment of bronchial wall attenuation with thin-section CT: an indicator of airflow limitation in chronic obstructive pulmonary disease. AJR Am J Roentgenol 195(2):363-369

74. Williamson JP, James AL, Phillips MJ, Sampson DD, Hillman DR, Eastwood PR (2009) Quantifying tracheobronchial tree dimensions: methods, limitations and emerging techniques. Eur Respir J 34(1):42-55

75. Kim N, Seo JB, Song KS, Chae EJ, Kang SH (2008) Semiautomatic measurement of the airway dimension by computed tomography using the full-width-half-maximum method: a study on the measurement accuracy according to the CT parameters and size of the airway. Korean J Radiol 9(3):226-235

76. Achenbach T, Weinheimer O, Dueber C, Heussel CP (2009) Influence of pixel size on quantification of airway wall thickness in computed tomography. J Comput Assist Tomogr 33(5): 725-730

77. Schmidt M, Kuhnigk JM, Krass S, Owsijewitsch M, Hoop BJ, Peitgen H (2010) Reproducibility of airway wall thickness measurements. Proc SPIE 7624(10)

78. de Jong PA, Long FR, Nakano Y (2006) Computed tomography dose and variability of airway dimension measurements: how low can we go? Pediatr Radiol 36(10):1043-1047

79. Tschirren J, Hoffman EA, McLennan G, Sonka M (2005) Intrathoracic airway trees: segmentation and airway morphology analysis from low-dose CT scans. IEEE Trans Med Imaging 24(12):1529-1539

80. Brillet PY, Fetita CI, Capderou A, Mitrea M, Dreuil S, Simon JM, Preteux F, Grenier PA (2009) Variability of bronchial measurements obtained by sequential CT using two computerbased methods. Eur Radiol 19(5):1139-1147

81. Hashimoto M, Tate E, Watarai J, Sasaki M (2006) Air trapping on computed tomography images of healthy individuals: effects of respiration and body mass index. Clin Radiol 61(10):883-887

82. Tanaka N, Matsumoto T, Miura G, Emoto T, Matsunaga N, Ueda K, Lynch DA (2003) Air trapping at CT: high prevalence in asymptomatic subjects with normal pulmonary function. Radiology 227(3):776-785

83. Lee KW, Chung SY, Yang I, Lee Y, Ko EY, Park MJ (2000) Correlation of aging and smoking with air trapping at thinsection CT of the lung in asymptomatic subjects. Radiology 214(3):831-836 
84. Chen D, Webb WR, Storto ML, Lee KN (1998) Assessment of air trapping using postexpiratory high-resolution computed tomography. J Thorac Imaging 13(2):135-143

85. Webb WR, Stern EJ, Kanth N, Gamsu G (1993) Dynamic pulmonary CT: findings in healthy adult men. Radiology 186(1): $117-124$

86. Mastora I, Remy-Jardin M, Sobaszek A, Boulenguez C, Remy J, Edme JL (2001) Thin-section CT finding in 250 volunteers: assessment of the relationship of CT findings with smoking history and pulmonary function test results. Radiology 218(3): 695-702

87. Regan EA, Hokanson JE, Murphy JR, Make B, Lynch DA, Beaty TH, Curran-Everett D, Silverman EK, Crapo JD (2010) Genetic epidemiology of COPD (COPDGene) study design. COPD 7(1):32-43

88. Jain N, Covar RA, Gleason MC, Newell JD Jr, Gelfand EW, Spahn JD (2005) Quantitative computed tomography detects peripheral airway disease in asthmatic children. Pediatr Pulmonol 40(3):211-218

89. Matsuoka S, Kurihara Y, Yagihashi K, Nakajima Y (2007) Quantitative assessment of peripheral airway obstruction on paired expiratory/inspiratory thin-section computed tomography in chronic obstructive pulmonary disease with emphysema. J Comput Assist Tomogr 31(3):384-389

90. Torigian DA, Gefter WB, Affuso JD, Emami K, Dougherty L (2007) Application of an optical flow method to inspiratory and expiratory lung MDCT to assess regional air trapping: a feasibility study. AJR Am J Roentgenol 188(3):W276-W280

91. Kurosawa H, Kohzuki M (2004) Images in clinical medicine. Dynamic airway narrowing. N Engl J Med 350(10):1036

92. Sverzellati N, Rastelli A, Chetta A, Schembri V, Fasano L, Pacilli AM, Di SV, Bartalena T, De FM, Zompatori M (2009) Airway malacia in chronic obstructive pulmonary disease: prevalence, morphology and relationship with emphysema, bronchiectasis and bronchial wall thickening. Eur Radiol 19(7):1669-1678

93. Ohara T, Hirai T, Muro S, Haruna A, Terada K, Kinose D, Marumo S, Ogawa E, Hoshino Y, Niimi A, Chin K, Mishima M (2008) Relationship between pulmonary emphysema and osteoporosis assessed by $\mathrm{CT}$ in patients with COPD. Chest 134(6):1244-1249

94. Bon J, Fuhrman CR, Weissfeld JL, Duncan SR, Branch RA, Chang CC, Zhang Y, Leader JK, Gur D, Greenspan SL, Sciurba FC (2011) Radiographic emphysema predicts low bone mineral density in a tobacco-exposed cohort. Am J Respir Crit Care Med 183(7):885-890

95. Diaz AA, Bartholmai B, San Jose ER, Ross J, Matsuoka S, Yamashiro T, Hatabu H, Reilly JJ, Silverman EK, Washko GR (2010) Relationship of emphysema and airway disease assessed by CT to exercise capacity in COPD. Respir Med 104(8): $1145-1151$

96. Han MK, Bartholmai B, Liu LX, Murray S, Curtis JL, Sciurba FC, Kazerooni EA, Thompson B, Frederick M, Li D, Schwarz M, Limper A, Freeman C, Landreneau RJ, Wise R, Martinez FJ (2009) Clinical significance of radiologic characterizations in COPD. COPD 6(6):459-467

97. Han MK, Kazerooni EA, Lynch DA, Liu LX, Murray S, Curtis JL, Criner GJ, Kim V, Bowler RP, Hanania NA, Anzueto AR, Make BJ, Hokanson JE, Crapo JD, Silverman EK, Martinez FJ, Washko GR (2011) Chronic obstructive pulmonary disease exacerbations in the COPDGene Study: associated radiologic phenotypes. Radiology 261(1):274-282

98. Grydeland TB, Dirksen A, Coxson HO, Eagan TM, Thorsen E, Pillai SG, Sharma S, Eide GE, Gulsvik A, Bakke PS (2010) Quantitative computed tomography measures of emphysema and airway wall thickness are related to respiratory symptoms. Am J Respir Crit Care Med 181(4):353-359

99. Mets OM, Murphy K, Zanen P, Gietema HA, Lammers JW, van Ginneken B, Prokop M, de Jong PA (2011) The relationship between lung function impairment and quantitative computed tomography in chronic obstructive pulmonary disease. Eur Radiol. doi:10.1007/s00330-011-2237-9

100. Haruna A, Muro S, Nakano Y, Ohara T, Hoshino Y, Ogawa E, Hirai T, Niimi A, Nishimura K, Chin K, Mishima M (2010) CT scan findings of emphysema predict mortality in COPD. Chest 138(3):635-640

101. Cederlund K, Tylen U, Jorfeldt L, Aspelin P (2002) Classification of emphysema in candidates for lung volume reduction surgery: a new objective and surgically oriented model for describing CT severity and heterogeneity. Chest 122(2):590-596

102. Nakano Y, Coxson HO, Bosan S, Rogers RM, Sciurba FC, Keenan RJ, Walley KR, Pare PD, Hogg JC (2001) Core to rind distribution of severe emphysema predicts outcome of lung volume reduction surgery. Am J Respir Crit Care Med 164(12): 2195-2199

103. Flaherty KR, Kazerooni EA, Curtis JL, Iannettoni M, Lange L, Schork MA, Martinez FJ (2001) Short-term and long-term outcomes after bilateral lung volume reduction surgery: prediction by quantitative CT. Chest 119(5):1337-1346

104. Martinez FJ, Foster G, Curtis JL, Criner G, Weinmann G, Fishman A, DeCamp MM, Benditt J, Sciurba F, Make B, Mohsenifar Z, Diaz P, Hoffman E, Wise R (2006) Predictors of mortality in patients with emphysema and severe airflow obstruction. Am J Respir Crit Care Med 173(12):1326-1334

105. Rogers RM, Coxson HO, Sciurba FC, Keenan RJ, Whittall KP, Hogg JC (2000) Preoperative severity of emphysema predictive of improvement after lung volume reduction surgery: use of CT morphometry. Chest 118(5):1240-1247

106. Stockley RA, Parr DG, Piitulainen E, Stolk J, Stoel BC, Dirksen A (2010) Therapeutic efficacy of alpha-1 antitrypsin augmentation therapy on the loss of lung tissue: an integrated analysis of 2 randomised clinical trials using computed tomography densitometry. Respir Res 11:136

107. Parr DG, White AJ, Bayley DL, Guest PJ, Stockley RA (2006) Inflammation in sputum relates to progression of disease in subjects with COPD: a prospective descriptive study. Respir Res 7:136

108. Dirksen A, Dijkman JH, Madsen F, Stoel B, Hutchison DC, Ulrik CS, Skovgaard LT, Kok-Jensen A, Rudolphus A, Seersholm N, Vrooman HA, Reiber JH, Hansen NC, Heckscher T, Viskum K, Stolk J (1999) A randomized clinical trial of alpha(1)-antitrypsin augmentation therapy. Am J Respir Crit Care Med 160(5 Pt 1):1468-1472

109. Dowson LJ, Guest PJ, Stockley RA (2001) Longitudinal changes in physiological, radiological, and health status measurements in alpha(1)-antitrypsin deficiency and factors associated with decline. Am J Respir Crit Care Med 164(10 Pt 1): 1805-1809

110. Stolk J, Ng WH, Bakker ME, Reiber JH, Rabe KF, Putter H, Stoel BC (2003) Correlation between annual change in health status and computer tomography derived lung density in subjects with alpha1-antitrypsin deficiency. Thorax 58(12):1027-1030

111. Stolk J, Putter H, Bakker EM, Shaker SB, Parr DG, Piitulainen E, Russi EW, Grebski E, Dirksen A, Stockley RA, Reiber JH, Stoel BC (2007) Progression parameters for emphysema: a clinical investigation. Respir Med 101(9):1924-1930

112. Yuan R, Hogg JC, Pare PD, Sin DD, Wong JC, Nakano Y, McWilliams AM, Lam S, Coxson HO (2009) Prediction of the rate of decline in FEV(1) in smokers using quantitative computed tomography. Thorax 64(11):944-949 
113. Ohara T, Hirai T, Sato S, Terada K, Kinose D, Haruna A, Marumo S, Nishioka M, Ogawa E, Nakano Y, Hoshino Y, Ito Y, Matsumoto H, Niimi A, Mio T, Chin K, Muro S, Mishima M (2008) Longitudinal study of airway dimensions in chronic obstructive pulmonary disease using computed tomography. Respirology 13(3):372-378

114. Makita H, Nasuhara Y, Nagai K, Ito Y, Hasegawa M, Betsuyaku T, Onodera Y, Hizawa N, Nishimura M (2007) Characterisation of phenotypes based on severity of emphysema in chronic obstructive pulmonary disease. Thorax 62(11):932-937

115. Kim WD, Ling SH, Coxson HO, English JC, Yee J, Levy RD, Pare PD, Hogg JC (2007) The association between small airway obstruction and emphysema phenotypes in COPD. Chest 131(5):1372-1378

116. Boschetto P, Miniati M, Miotto D, Braccioni F, De RE, Bononi I, Papi A, Saetta M, Fabbri LM, Mapp CE (2003) Predominant emphysema phenotype in chronic obstructive pulmonary. Eur Respir J 21(3):450-454

117. Orlandi I, Moroni C, Camiciottoli G, Bartolucci M, Pistolesi M, Villari N, Mascalchi M (2005) Chronic obstructive pulmonary disease: thin-section CT measurement of airway wall thickness and lung attenuation. Radiology 234(2):604-610

118. Alford SK, van Beek EJ, McLennan G, Hoffman EA (2010) Heterogeneity of pulmonary perfusion as a mechanistic imagebased phenotype in emphysema susceptible smokers. Proc Natl Acad Sci USA 107(16):7485-7490
119. Han MK, Agusti A, Calverley PM, Celli BR, Criner G, Curtis JL, Fabbri LM, Goldin JG, Jones PW, MacNee W, Make BJ, Rabe KF, Rennard SI, Sciurba FC, Silverman EK, Vestbo J, Washko GR, Wouters EF, Martinez FJ (2010) Chronic obstructive pulmonary disease phenotypes: the future of COPD. Am J Respir Crit Care Med 182(5):598-604

120. Fujimoto K, Kitaguchi Y, Kubo K, Honda T (2006) Clinical analysis of chronic obstructive pulmonary disease phenotypes classified using high-resolution computed tomography. Respirology 11(6):731-740

121. Kitaguchi Y, Fujimoto K, Kubo K, Honda T (2006) Characteristics of COPD phenotypes classified according to the findings of HRCT. Respir Med 100(10):1742-1752

122. Mets OM, Buckens CF, Zanen P, Isgum I, van GB, Prokop M, Gietema HA, Lammers JW, Vliegenthart R, Oudkerk M, van Klaveren RJ, de Koning HJ, Mali WP, de Jong PA (2011) Identification of chronic obstructive pulmonary disease in lung cancer screening computed tomographic scans. JAMA 306(16): 1775-1781

123. Brenner DJ, Doll R, Goodhead DT, Hall EJ, Land CE, Little JB, Lubin JH, Preston DL, Preston RJ, Puskin JS, Ron E, Sachs RK, Samet JM, Setlow RB, Zaider M (2003) Cancer risks attributable to low doses of ionizing radiation: assessing what we really know. Proc Natl Acad Sci USA 100(24):13761-13766 